\title{
Toplam Kalite Yönetimi Açısından İç Denetimin Değerlendirilmesi
}

\author{
DOI: 10.26466/opus.584135
}

*

Alirıza A $\breve{g}^{*}$ - Elif Çil**

* Dr. Öğr. Üyesi, Bayburt Üniversitesi, İktisadi İdari Bilimler Fakültesi, 69000, Bayburt / Türkiye E-Posta: alirizaag@bayburt.edu.tr ORCID: 0000-0001-5345-6245

** Uzman Yardımcısı, Bayburt İl Telekom Müdürlügü̈, 69000, Bayburt / Türkiye E-Posta: elif_cil_69@hotmail.com

ORCID: 0000-0002-3364-0464

\section{Öz}

Toplam Kalite Yönetimi, teknolojinin ilerlemesiyle birlikte artan rekabet koşullarında, sınırsız ve birbirinden bağımsız olan müşteri ihtiyaç ve gereksinimlerini en iyi şekilde karşılayan, aynı zamanda bu işlemleri en az maliyetle yapan bir yönetim felsefesidir. İç denetim ise, işletme kaynaklarının etkin ve verimli şekilde kullanılmasına yardımo olan, bir kuruluşun yapmış olduğu faaliyetleri geliştirmek ve yönetim faaliyetlerine değer katmak için yapılan tarafsız, bağımsız bir güvence ve danışmanlık faaliyetidir. Geçmişten günümüze kadar işletmelerin yönetim tarzlarındaki değişiklikler Toplam Kalite Yönetim sisteminin denetim kavramına bakış açısını değiştirmiştir. Denetimler dinamik bir yapıda ve sürekli yenilenerek işletmedeki tüm faaliyetlerin denetimini sağlamaktadır. Çalışmada, tarih boyunca karşılıkı etkileşim içinde olan Toplam Kalite Yönetimi (TKY) ve İç Denetim Sisteminin birbirleri ile olan etkileşimi incelenmiştir. Çalışma sonucunda; İç Denetim Sistemi ve Toplam Kalite Yönetim Sisteminin birbirlerini doğrudan ya da dolaylı şekilde etkiledikleri ve değer kattıkları bunun sonucunda da işletmelerdeki Iç Denetim fonksiyonun Toplam Kalite Yönetimi uygulamalarından kaynaklanan maliyetleri düşürdüğ̈̈ ve verimliliği artırdığı tespit edilmiştir.

Anahtar Kelimeler: TKY, Iç Denetim, $\dot{I}_{c ̧}$ Kontrol 


\title{
Evaluation of Internal Audit from Total Quality Management
}

\begin{abstract}
Total Quality Management is a management philosophy that works at minimum cost, whether the customer service and needs are unlimited and independent from each other in the best conditions under increasing competition conditions with the advancement of technology. Internal auditing is an objective, independent assurance and cooperation activity that helps the management of operating resources effectively and efficiently, helps establish an organization and conduct management activities to add value. From the past to the present, general Quality Audits in the management styles of the factory are in a dynamic structure and continuously renewed and control of all activities in the enterprise. The interaction between Total Quality Management (TQM) and Internal Audit System was examined. Operation; The internal management system and the total quality management system directly or indirectly affect and add value to different parts of the current management center in this regard is the board of directors.
\end{abstract}

Keywords: TQM, Internal Audit, Internal Control 


\section{Giriş}

Teknolojinin hızla gelişmesi, tüketici ihtiyaç ve isteklerini artırmış, bunun sonucunda ise işletmeler arası rekabet artmıştır. İşletmeler de bu rekabet ortamında ayakta kalabilmek ve varlıklarını devam ettirebilmek için yeni çözüm yöntemleri arayışına girmişlerdir. İşletmeler, üretim kapasitesinin artmasıyla sınırsız olan müşteri ihtiyaç ve gereksinimlerini karşılamak üzere kalite geliştirme çalışmaları yapmışlardır. Ayrıca işletmeler, yıllar içerisinde yönetim geliştirme çalışmaları yaparak, kalite anlayışının sadece ürün odaklı değil müşteri odaklı olması gerektiğini ortaya çıkarmışlardır. Hammurabi yasalarıyla ortaya çıkan kalite kavramı muayenecilik anlayışı ile devam etmiş yıllar içerisinde kalite kontrol, kalite güvence ve 1980'lerden sonra ortaya çıkan Toplam Kalite Yönetimi (TKY) sistemi ile günümüze kadar gelişerek gelmiştir.

Günümüz işletmelerinde rekabet ortamında üstünlük sağlayabilmek için benimsenen TKY, müşterilerin ihtiyaç ve gereksinimlerinin doğru tespit edilerek karşılanmasını, müşteri memnuniyetinin artırılmasını ve maliyetlerin azaltılmasını sağlayan bir yönetim anlayışıdır. İşletmelerin varlıklarını doğru ve etkin şekilde kullandığını tespit edilmesi için özgür ve tarafsız bir bakış açısıyla değerlendirilmesi gerekmektedir (Yurdbulan, 1998, s.1). Odak noktası müşteri memnuniyeti olan TKY'de müşterilere güven oluşturulması oldukça önemlidir. Bu güveni oluşturabilmek için iç denetim kavramı ortaya çıkmıştır. İç denetim; bir kuruluşun yapmış olduğu faaliyetleri geliştirmek ve bu faaliyetlere değer katmak için yapılan bağımsız, tarafsız bir güvence ve danışmanlık sistemi olarak tanımlanmaktadır (Özçelik, 2008, s.1). İç denetimler, işletmelerde kalite ile ilgili yapılan çalışmaların etkin ve verimli olarak gerçekleşmesine ve kalite maliyetlerinin düşürülmesine katkı sağlamaktadır. Kalite kavramının önemli olduğu günümüz dünyasında yönetim unsurlarından olan TKY ve İç Denetim birbirleriyle tarih boyunca doğrudan ya da dolaylı olarak etkilemiş ve birbirlerine olumlu yönde katkı sağlamışlar.

\section{Toplam Kalite Yönetimi ve Kalite Denetimleri}

Ekonominin lokomotifi olan işletmelerin kendilerine özgü bir misyonu bulunmaktadır. İşletmeler bu misyonlarını gerçekleştirmek ve hedeflerine 
ulaşabilmek için çeşitli stratejiler uygulamaktadır. Toplam Kalite Yönetimi bu startejilerden biridir. Toplam Kalite Yönetim araçlarından olan kalite denetimleri ile işletmede etkinlik ve verimlilik artırılırken maliyetlerin azaltılması sağlanır.

\section{Kalite Kavramı ve Toplam Kalite Yönetimi}

Ekonominin hızla geliştiği günümüz dünyasında teknolojide meydana gelen gelişmelerle küresel rekabet artmış bu da işletmeleri müşteri ihtiyaç ve gereksinimlerine yönelik çalışmalar yapmaya yönlendirmiştir. Sonu olmayan müşteri beklentilerine işletmelerin yetebilmesi neredeyse imkansızdır. Bu yüzden işletmelerin öncelikle hedef müşteri kitlesi belirleyip bu müşterilerin talep ve ihtiyaçlarına göre ürünler üretmeleri gerekmektedir. Üretilen bu ürünler o hedef kitlesi için kaliteli anlamına gelmektedir (Özevren, 1997, s.62).

Kalite kavramının anlamı kullanıcı bakış açısından dolayı değişiklik göstermektedir. Bir müşteri için kaliteli olan bir ürün özelliği başka bir müşteri için kalitesiz niteliğinde olabilmektedir. Bu yüzden kalite ile ilgili sınırsız tanım ve yorum yapılabilmektedir. Ancak kalite ile ilgili genel olarak kabul gören tanımlar şöyledir: Kalite, ihtiyaca uygunluk, şartlara uygunluk ve kullanıma uygunluktur (Yükçü, 1999, s.4-5). Kalite kavramına ilk olarak M.Ö. 18. yy'da Mezopotamya ortaya çıkan, tarihin en eski ve en iyi korunmuş olan 282 maddelik Hammurabi yasalarında rastlanmıştır. İlgili yasada “Eğer bir inşaat ustası bir adama ev yaparsa ve yapılan ev yeterince sağlam olmayıp ev sahibinin üstüne çökerek ölümüne sebep olursa o inşaat ustasının başı uçurulur." maddesiyle o dönemlerde kaliteye verilen önemden bahsedilmiştir. Kalite kavramı, sürekli gelişen ve iyileşen bir kavramdır. Sanayi devriminin ardından ürünler üretildikten sonra muayeneciler ortaya çıkmış ve tüketiciye kusurlu ürünlerin ulaşmasını engellenmişlerdir. Bu durum tüketiciler için olumlu, üreticiler için oldukça maliyetli olmuştur. 1920'lerden sonra ürün üretilirken ara ara kontroller yapılmış ve standartlara uygunluk tespit edilmiştir. II. Dünya Savaşı'ndan sonra ürün veya hizmet alan müşteriye güven sağlayacak sistemler ortaya çıkmıştır. 1980'lerden sonra ise tüm dünyaya yayılan Toplam Kalite Yönetimi kavramı ortaya çıkmıştır. Şekil 1' 
de günümüze kadar gelen kalite evrimi gösterilmektedir (Tütüncü, 1998, s.10).

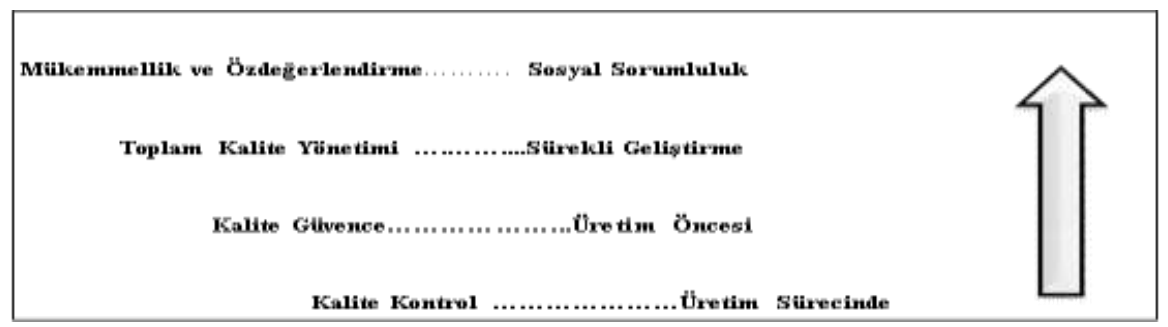

Şekil 1. Kalite Evrimi

Tüm dünyada hızla yayılan ve günümüzde birçok işletme tarafından benimsenen Toplam Kalite Yönetimi, müşteri istek ve ihtiyaçlarına cevap verirken maliyetlerin düşürülmesini sağlayan önemli bir yönetim anlayışıdır. Toplam Kalite Yönetimi, kelimelerinin baş harflerinden oluşan TKY olarak bilinmektedir. Şekil 2'de kalite kavramlarının birbirleriyle olan ilişkisi gösterilmiştir (Akçal, 2005, s.16).

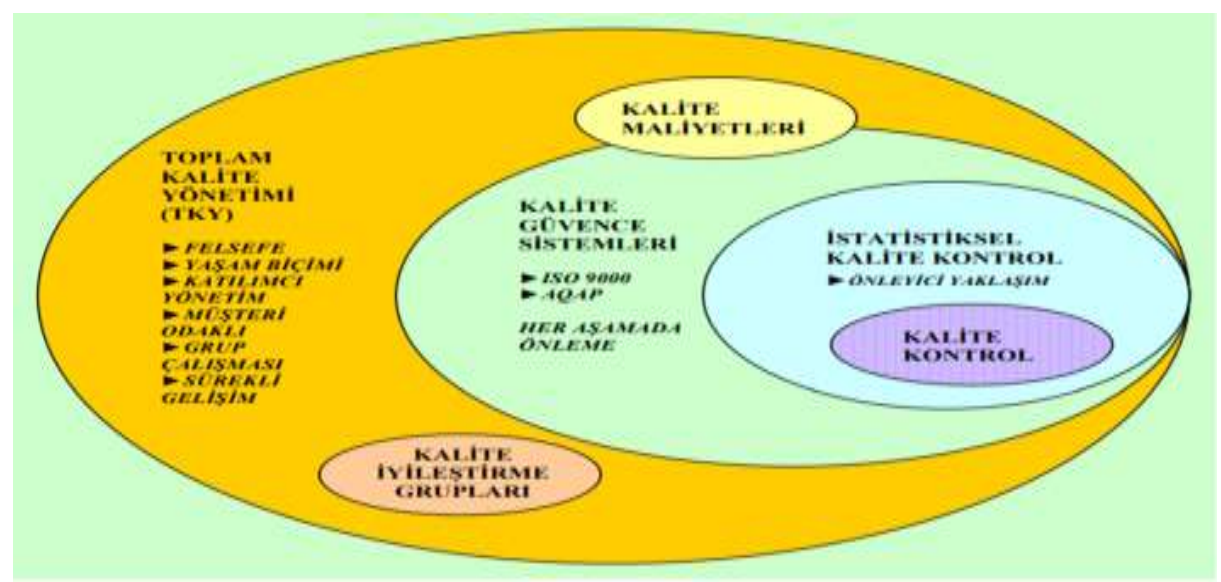

Şekil 2. Kalite Kavramlarının Birbiri ile İlişkisi

TKY, ilk olarak Henry Ford tarafından 1926 yılında yayınlamış olduğu kitabında tanımlanmıştır. Ancak o dönemlerde bu görüş sadece Japonlar tarafından rağbet görmüştür. Japonlar, Henry Ford tarafından ortaya atılan yönetim tarzını işletmelerinde uygulamış ve tüm çalışanların katılımını sağlayarak bunu bir yönetim felsefesi haline getirmişlerdir. Bir 
yönetim felsefesi olan TKY'nin odak noktası müşterilerdir. TKY'de sadece ölçülebilen değerler değil ölçülemeyen değerler de dikkate alınmaktadır (Ertuğrul, 2014, s.134). TKY uygulayan işletmeler bu yönetim tarzının kısa dönemde çok fazla etkisini görmesede uzun dönemde müşteri beklentilerinin karşılanması konusunda yararını görmektedir. En üst yöneticiden en alt çalışana kadar tüm personeli kapsayan TKY'de ekip çalışması oldukça önemlidir. Aynı zamanda sıfır hata prensibiyle çalışılması işletmede meydana gelebilcek hataların engellenmesini sağlar. TKY insan odaklı bir yaklaşım olduğu için çalışan motivasyonu ve çalışanların ödüllendirilmesi oldukça önemlidir. TKY, Klasik yönetim anlayışında olduğu gibi hata odaklı bir sistem değildir. TKY'de sürekli iyileştirme yapılarak müşteri memnuniyeti sağlanmaktadır. Muhittin Şimşek Kalite Yönetimi Kitabında TKY'nin amaçlarından aşağıdaki şekilde bahsetmiştir (Şimşek, 1998, s.108):

- İşletmedeki tüm çalışanların ekip çalışmasına katılması

- Kaizen denilen sürekli iyileştirme ve geliştirme yaklaşımının tüm işletmede yaygınlaştırlması

- Kalitede en üst noktaya ulaşılması

- İşletmenin sıfır hata prensibiyle çalışarak maliyetlerin düşürülmesinin sağlaması

- Çalışan motivasyonuna önem verilmesi ve çalışanların ödüllendirilmesi

- İşlem sürelerini azaltarak teslim hızının artırılması

- Müşteri güveninin kazanılması

TKY ile asıl amacı daha fazla kâr elde etmek olan işletmelerin, ürün üretilmeden gerekli önlemlerin alınması ile daha az hata yapması ve özellikle başarısızlık maliyetlerinin azalması sağlanır. İşletmelerde uygulanan TKY sisteminin uygulama sonuçları ise aşağıdaki gibi özetlenebilir (Macdonald, 1999, s.13):

- Çok iyi geliştirilmişürün veya hizmet ortaya çıkması

- Üretimde artış yaşanması

- Üst yönetim ve çalışanlar arasında etkili iletişim kurulması

- Çalışanların motive edilmesi ve ödüllendirilmesiyle ortaya ç1kan memnun işgücü

- Uzun vadede pazar payında artış sağlanması

- Kâr artırımı için fırsattır. 


\section{Kalite Güvence Sistemi}

İşletmelerde kalite sisteminin temelinde müşteri memnuniyeti bulunmaktadır. Sınırsız olan tüketici ihtiyaç ve gereksinimleri işletmelerde farklı kalite sistemlerini ortaya çıkartmıştır. Müşteri beklentilerini karşılamak amaciyla kurulmuş olan kalite güvence sistemi, işletmelerin belirlenen kalite hedeflerine ulaşabilmesi için uyguladığ yetlerdir (Özevren, 1997, s.40).

Kalite güvence sistemi, Toplam Kalite Yönetiminin uygulanması için oldukça önemlidir. Kalite güvence sistemleri politika ve prosedürler çerçevesinde belirlenen görev ve sorumlulukları içermektedir. $\mathrm{Bu}$ prosedürlerin hepsinin toplandığ kalite el kitabı, Toplam Kalite Yönetiminin felsefesini oluşturmaktadır (Kocabaş, 2013, s.1).

\section{Kalite Denetimleri}

Artan rekabet ortamında işletmeler için çok önemli bir kavram olan kalitenin sürekli iyileştirilmesi ve geliştirilmesi, işletmelerin yoğun çalışmalar yapmasını sağlamıştır. Bu durumda işletmeler uygulamadaki etkinliğin ölçülebilmesi için kalite denetimleri yapmaya başlamışlardır (Dalak, 2000, s.2). Kalite denetimleri; yapılan çalışmalar ve bu çalışmaların sonuçlarının belirlenen hedeflere uyup uymadığını ölçen bağımsız sistemler olarak tanımlanmaktadır. Kalite denetimleri ile işletmedeki uygunsuzluklar tespit edilerek gerekli önlemler alınmaktadır. Böylece ortaya çıkan uygunsuzluklar ya azaltılmakta ya da tamamen ortadan kaldırılmaktadır. Kalite denetimleri ikiye ayrılmaktadır. Bunlar Kuruluş İçi Kalite Denetimleri ve Kuruluş Dışı Kalite Denetimleridir.

\section{Kuruluş İçi Kalite Denetimleri}

İşletmedeki Kalite Güvence bölümü tarafından yapılan kuruluş içi kalite denetimleri; işletmede uygulanan kalite sisteminin yeterli olup olmadığını ayrıca sisteme uygunluğunu tespit eden denetimlerdir. Kuruluş içi kalite denetimler, işletmenin zayıf ve geliştirilmesi gereken noktalarını tespit ederek tüm çalışanların düzeltici, önleyici, iyileştirici faaliyetlere katılımını sağlamaktadır (Aytimur, 1999, s.20). TKY için oldukça önemli 
olan kuruluş içi kalite denetimleri, işletmede etkinlik ve verimliliğin artırılmasını sağlamaktadır.

\section{Kuruluş Dışı Kalite Denetimleri}

Klasik yönetim anlayışında sadece ölçülebilen değerler dikkate alınırken TKY sisteminde ölçülebilen değerlerin yanında ölçülemeyen değerler de dikkate alınmaktadır. Bunlardan en önemlisi dış başarısızlık maliyetlerini etkileyen müşteri geri dönüşleridir. Kuruluş dışı kalite denetimleri ile önce müşteri tatmini sağlanmaktadır. Daha sonra bu denetimler ile işletme gelişimine yönelik çalışmalar yapılmakta sonuç olarak da sistemin olumsuz ve eksik yönleri erken tespit edilerek düzeltilmektedir.

\section{3. İç Denetim Sistemi ve İç Kontrol Sistemi}

Denetim kelimesi M.Ö. 3000'li yıllara dayanmaktadır. Denetim, Latince kökenli bir kelimedir ve audit kelimesinden türemektedir. Denetim kelime anlamı olarak duyma ve dinleme faaliyetleri ile ilgili olan yargılar anlamına gelmektedir. Daha geniş anlamda ise denetim, bir bilgi hakkında kanıtların toplanması, değerlendirilmesi ve rapor edilmesi anlamına gelmektedir. Denetimler, işletmedeki iç ve diş tehditlerin tespit ederek işletmeye gelecek olan zararların ortadan kaldırılmasını sağlamaktadır (Aktuğlu, 1986, s.7). Ayrıca denetimler, işletmede birimler arasındaki farklılıkların düzeltilmesine veya ortadan kaldırılmasına olanak sağlamaktadır (Başpınar, 2005, s.35). Denetimler, işletmelerin amaçlarına verimli bir şekilde ve zamanında ulaşıp ulaşmadığını tayin etmektedir. Denetimin üç ana öğesi bulunmaktadır. Bunlar (Köksal, 1974, s.52);

1. Ulaşılmak istenen örgütün ana amaçlarının bulunması

2. Belirlenen amaçlara verimli şekilde ulaşılması

3. Belirlenen amaç ve sonuçlara zamanında ulaşılmasıdır.

Denetimin asıl amacı; istenilen amaç ile gerçekleşen durumun karşılaştırılmasını sağlamaktır. Denetimler var olanla olması gerekeni karşılaştırarak, varsa uygunluk veya sapmalardan hangisinin daha fazla olduğunu tespit etmektedir (Örnek, 1992, s.248). Denetçi statüsüne göre denetimler iç denetim ve diş denetim olarak ikiye ayrılmaktadır. Bu 
çalışmada iç denetimden bahsedilecektir. İşletmelerde uygulanan etkili bir iç denetimin tek başına yeterli olmadığı göz ardı edilmemelidir. Bu nedenle işletmelerde bağımsız denetçilerin olduğu diş denetimlerin de yapılması gerekmektedir.

\section{a. İç Denetim Sistemi}

Küreselleşmeyle birlikte günümüz dünyasında artan rekabet ortamında risklerin yönetimi ve müşteriler açısından işletmelerin güvenilir olması oldukça önem arz etmektedir. Teknolojik gelişmelerin artması ile büyüyen işletmelerde, iç kontrol sistemi oluşturularak iç denetim yapılması müşteriler için güven ortamı oluşturması açısından önemli hale gelmiştir. İç denetim ilk olarak kâr amacı gütmeyen işletmeler ve devlet işletmelerinde kullanılmaya başlanmıştır (Yurdbulan, 1998, s.5). Daha sonra işletmelerin büyümeye ve kurumsal hale gelmeye başlamasıyla iç denetim diğer işletmeler tarafından da benimsenmiştir. İç denetim, bir kuruluşun yapmış olduğu faaliyetleri geliştirmek ve onlara değer katmak için yapılan bağımsız bir güvence ve danışmanlık faaliyeti anlamına gelmektedir. Başka bir ifade ile; iç denetim, iç denetçiler tarafından finansal ve finansal olmayan faaliyetlerin ve kontrollerin sistematik olarak değerlendirilmesi süreci demektir (Uzay, 1999, s.35-36). Temelinde güven esas olan denetimler nerede yapılırsa yapılsın uyulması gereken bazı ilkeler bulunmaktadır. Bunlar; bağımsızlık, yasallık, nesnellik-tarafsızlık ve dürüstlük kavramlarıdır (Akpinar, 2006, s.31).

- Bağımsızlık kavramı: Denetim çalışmalarının dürüst ve tarafsız olarak yürütülmesi anlamına gelmektedir. Bağımsızlık denetimin temelini oluşturmaktadır. Bağımsız denetçiler yönetim tarafından belirlenen ancak görüşlerini açıkça ifade etmelidir (Sezal, 2006, s.77)

- Yasallık kavramı: İşletmelerde yapılan denetimlerin yasalara uygun olarak yürütülmesi ve yasallığın denetlenmesi anlamlarına gelmektedir. Yasallığın denetimi, denetimin konusu olarak tanımlanmaktadır. Hukuka uygunluk denetimi ise işletmede yapılan denetimlerin yasalara uygunluğunun denetlenmesidir (Atay, 1999, s.32).

- Nesnellik-tarafsızlık kavramı: Denetim yapan işletmelerde denetçilerin tarafsız olmaları gerekmektedir. Yönetimin etkisi altında olmadan görevlerini yerine getirmeli ve ortaya çıkacak çıkar çatışmalarından 
uzak durmalıdır. Kimsenin etkisi altında kalmadan ortaya çıan sonuçları rapor edebilmelidir (Gürbüz, 1995, s.18).

- Dürüstlük kavramı: işletmelerde uygulanan denetimlerde dürüstlük kavramı da oldukça önemlidir. Bu kavram hem denetleyen hem de denetlenen ile ilgilidir. Denetlenen kişinin görev ve sorumluluklarının yerine getirip getirmediği denetleyen kişinin ise var olanı olduğu gibi rapor etmesi ile ilgilidir. Bir denetçinin doğru değerlendirme yapması ve doğru rapor oluşturması için maddi ve manevi açıdan tam bağımsız ve dürüst olması gerekmektedir.

İşletme büyüklüğü, iç denetim üzerinde önemli etkiye sahiptir. İç denetimin sadece işletme büyüklüğü ile değil işletme ortakları, işletmedeki faaliyetlerin çeşitliliği, veri değerlendirme yöntemleri ve yasal koşulların uygulanabilirliği ile birlikte değerlendirilmesi gerekmektedir (Bozkurt, 1995, s.30).

Uluslararası İç Denetçiler Enstitüsü (2012) (The Institute of Internal Auditors-IIA) iç denetimi şu şekilde tanımlamıştır; “İç denetim, bir kurumun yapmış olduğu faaliyetleri geliştirmek ve onlara değer katmak amacıyla yapılan bağımsız, tarafsız bir güvence ve danışmanlık faaliyetidir." Özetle iç denetim; bir işletmedeki mali ve mali olmayan faaliyetlerin ve kontrollerin, iç denetçiler tarafından sistematik ve objektif olarak değerlendirilmesi anlamına gelmektedir (Sawyer, 1988, s.20).

İç denetimler, işletmedeki üst yönetimi ilgilendirmektedir. İç denetim, iç denetçi denilen işletme personelleri tarafından yapılmaktadır. İç denetimi gerçekleştiren iç denetçiler üst yönetimin belirlemiş olduğu çerçeve dahilinde denetim yapmak zorundadırlar (Sezal, 2006, s.17).

İç denetimler işletmelerdeki hataların büyümeden tespit edilmesini sağlayarak işletmede meydana gelebilecek büyük problemlerin gerçekleşmeden önce çözümlenmesini sağlamaktadır.

İşletmelerde önemli bir yönetim aracı olan iç denetim faaliyetlerini gerektiren nedenlerden bazıları şöyle sıralanabilmektedir (Türedi, 2011, s.36-39):

- İşletmede üst yönetim ve diğer tüm çalışanların görevlerini etkin ve verimli şekilde yerine getirmelerinin sağlanması,

- İşletmedeki tüm personel ve yönetime hedeflerin başarılabilmesi için sorumluluk verilmesi,

- Denetim çalışmaları ile ilgili her çalışanın hesap vermesi, 
- İşletmedeki yöneticilere danışmanlık, çalışanlara ise eğitim hizmeti işlevi görmesi,

- İşletmede gerçekleşebilecek zararların ortaya çıkmadan önce tespit edilmesi ve düzeltilmesi.

- $\dot{I}_{c ̧}$ Denetim Standartlar

Uluslararası iç denetim standartları nitelik ve performans standartları olmak üzere ikiye ayrılmaktadır. İç denetim faaliyetlerini yürüten taraf ve kurumların özellikleri nitelik standartlarını, iç denetim faaliyetlerinin performansını değerlendirmek için kullanılan kalite ölçütlerinin sağlanması ise performans standartlarını oluşturmaktadır. Nitelik standartları, işletmede uygulanan iç denetim faaliyetlerinin amaç, yetki ve sorumluluklarının tanımlanması, bağımsızlık ve tarafsızlık, mesleki yeterlilik, mesleki özen ve dikkat, sürekli mesleki gelişim, kalite güvence ve geliştirme programlarını kapsarken; performans standartları, iç denetim faaliyetinin yönetimi, yapılacak işin niteliği, görev planlaması, görevin yapılması, sonuçların raporlanması, gelişmelerin izlenmesi, oluşabilecek risklerin yönetimce üstlenilmesini kapsamaktadır. İşletme üst yönetimi tarafından belirlenen iç denetçiler, işletmede yapacağı çalışmalarda bu standartları uygulamakla yükümlüdür. İç denetim standartlarının amaçları şöyledir (Karcıoğlu ve Yanık, 2010, s.231):

- İç denetimin temel ilkelerini tanımlamak

- Katma değerli iç denetim faaliyetlerini teşvik etmek

- İç denetimin doğru değerlendirilmesine uygun zemin oluşturmak

- Gelişmiş kurumsal süreç ve faaliyetleri canlandırmaktır.

\section{- $\quad \dot{I}_{c ̧}$ Denetimin İşletmelerde Uygulanma Süreci}

İç denetim, işletmelerde risk ve kontrol faaliyetlerinin uygunluğunu tespit ederek gerekli önlemlerin alınmasını sağlar. İç denetim ile işletmeler, mali raporlarının güvenirliliğini, yasalara ve düzenlenmelere uygunluğunu, işletme faaliyetlerinin etkinlik ve verimliliğini tespit etmektedir. İşletmeler için bu kadar önemli bir fonksiyon olan iç denetim süreci aşağıdaki 
şekilde gerçekleşmektedir (http://www.denetimnet.net/UserFiles/Documents/DeloitteMakaleleri/i\%C5\%9FLETMELERDE\%20Ba\%C5\%9Far\%C4\%B1\%20Fakt\%C3\%B6rleri.pdf, 25.05.2019).

> Belirlenen standartlara uygun olarak yönetim kurulu tarafından iç denetim yönetmeliğinin oluşturulması

$>$ İç denetimin işletmedeki yerinin belirlenmesi

> İç denetim çalışanları tarafından yönetici ve çalışanların yetki ve sorumluluklarının yazılı şekilde oluşturulması

$>$ Belirlenen süreç için gerekli görüşmeler yapılması, prosedürlerin incelenmesi ve iç kontrollerin değerlendirilmesi

$>$ İyileştirme önerilerinde bulunulması

> İşletmede ortaya çıkacak risk faktörlerinin değerlendirilmesinin yapilmasi

$>$ Yapılan risk değerlendirilmesinden sonra yıllık iç denetim planı oluşturulması ile iç denetim süreci uygulanmaktadır.

\section{b. İ̧ Kontrol Sistemi}

Kontrol, işletmeler tarafindan belirlenen hedeflerin eksiksiz şekilde verimli ve zamanında gerçekleşip gerçekleşmediğinin izlenmesidir. İşletmelerde yapılan kontroller sayesinde düzeltici önlemler alınmaktadır (Öztürk, 2003, s.326). İşletmeler, iç denetimden yararlanırken daha fazla fayda görebilmek için iç kontrol sistemine ihtiyaç duymaktadır. Bunun için iç denetim yapan her işletmenin kendine özgü iç kontrol sistemleri bulunmaktadır. İç kontrol sistemi işletmedeki birçok grubu ilgilendiren bir kavramdır. Bu sistem, işletmedeki faaliyetlerin etkinlik ve yeterlilik gibi hedeflerine ulaşmaları konusunda güvence vermek amacıyla oluşturulmuştur. Kanun ve düzenlemelere uygun olan bu sistemde işletme yönetimi ve çalışanlar aktif şekilde rol almaktadır (Schiff and May, 1990, s.37).

İç kontrol sistemi, sadece işletmedeki uygunsuzlukların bulunmasını tespit etmekle kalmaz bu uygunsuzlukların ortaya çıkmadan tespit edilip önlemlerin alınmasını da sağlar. İç kontrol sistemi ile işletmelerin yapmış olduğu faaliyetler kontrol edilmektedir. İç kontrol sistemi sayesinde yapılan bu kontrollerden sonra ortaya çıkan sonuçlar işletmelerin tüm 
faaliyetlerine etki etmektedir. İşletmede uygulanan düzeltici faaliyetler ile iç kontrol sistemi daha etkin hale gelmektedir (Ökten, 2004, s.30-31).

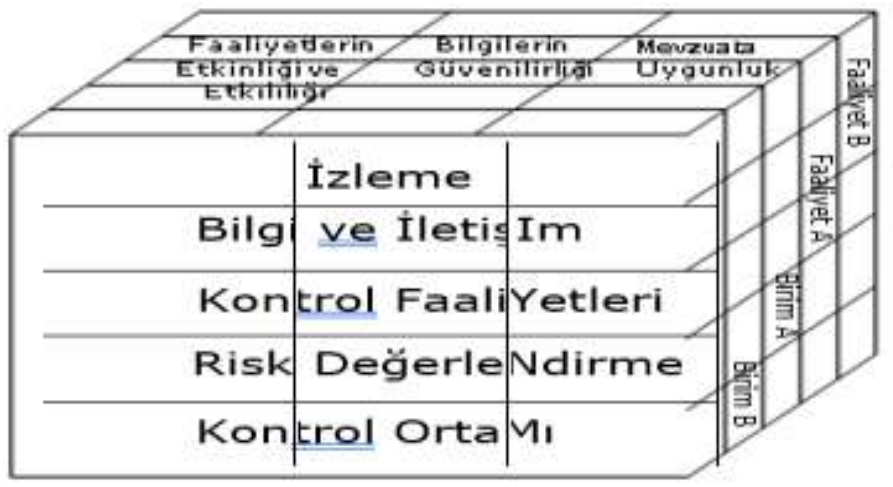

Şekil 3. COSO İç Kontrol Model

Şekil 3'te işletmelerin finansal raporlamalarının kalitesini arttırmak ve etkin bir iç kontrol sistemi oluşturmak amaciyla kurulmuş olan COSO iç kontrol modelinin dikey kolonları faaliyetlerin etkinliği ve etkililiği, bilgilerin güvenirliği ve mevzuata uygunluk olarak 3 kısımda gösterilmiştir. Yatay kolonlarda ise izleme, bilgi ve iletişim, kontrol faaliyetleri, risk değerlendirme, kontrol ortamı olarak 5 unsuru bulunmaktadır. Şekilde her unsurun amaçlarına ulaşabilmesi için birbirleriyle iç içe geçmiş olduğu görülmektedir (Pehlivanl1, 2010, s.33).

İç kontrol sisteminin üç ana amacı bulunmaktadır. Bunlardan birincisi; işletmedeki faaliyetlerin etkinlik ve verimliliğinin artırılmasıdır. Bir işletmede iç kontrol varsa işletme süreçlerinin tanımları, görev tanımları ve kurallar bulunmaktadır. Bu durum işletmelerin hedeflerine ulaşmasında önemli bir rol oynamaktadır. İkinci ana amacl; işletmenin dışarıdan algılanışını şekillendiren finansal raporlarının güvenirliliğini sağlamasıdır. $\mathrm{Bu}$ durum işletme yönetiminin doğru karar almasını ve meydana gelebilecek yolsuzlukların önlemesini sağlar. İç kontrol sisteminin üçüncü ana amacı ise; yasal düzenlemelere ve işletme içi kurallara uygunluğunun sağlanmasıdır.

İç denetim ve iç kontrol sistemi birbirinden farklı iki kavram olmakla birlikte aralarında karşılıklı ve olumlu yönde bir ilişki bulunmaktadır. İç kontrol sistemi iç denetim sistemini kavrayan bir sistemdir. Bununla 
birlikte iç denetim faaliyetlerinin doğru değerlendirilmesi için iç kontrol sisteminin doğru anlaşılması gerekmektedir. İç kontrol sistemi, işletmelerin hedeflerine ulaşmasını sağlayan, işletmelerde uygulanan plan, politika ve uygulamaları içeren tüm faaliyetleri kapsamaktadır (Özeren, 2000, s.3). İç kontrol sistemi ile, işletme görevleri alt görevlere ayrılarak her göreve farklı kişiler getirilmiş ve çeşitli sorumluluklar verilmiştir. Böylece işletmedeki çalışan personellerin birbirlerini kontrol etmeleri sağlanmıştır. Bu durum da hata ve hilelerin engellenmesini sağlamış ve kötü niyetli davranışlar engellenmiştir (Kaval, 2008, s.126).

\section{Toplam Kalite Yönetimi ve İç Denetim Sistemi Arasındaki İlişki}

İşletmelerin yakın tarihe kadar benimsemiş oldukları klasik yönetim anlayışında yönetim kavramı, işletmede var olan sistemlerin doğru şekilde çalıştırılması, işletmede içerisindeki sıkı disiplinler ile çalışanların işlerini doğru yapmalarının sağlanması ve maksimum kâr elde edilmesi olarak görülmektedir. Klasik yönetim anlayışında iç denetçiler, sadece birey odaklı bir denetim ile hata odaklı, suçlu aramaya yönelik ve suçlu olanların cezalandırılması yönünde hareket etmişlerdir. Bu yönetim anlayışında iç denetim yapan iç denetçilerin tüm çalışanlara suçlu gözüyle bakması muhtemeldir. Günümüzde benimsenen TKY sistemine göre ise "önce insan" anlayışı bulunmaktadır. TKY anlayışında iç denetçilerin hata odaklı ya da suçlu aramaya yönelik tutumları değil, takım ruhu içerisinde tüm çalışanlara hedefler konusunda sorumluluklar verilmesi çalışanların da denetçilere karşı olan olumsuz bakış açılarını değiştirmelerini sağlamıştır. Klasik yönetim anlayışında işin doğru yapılıp yapılmadığıyla ilgilenilirken TKY de doğru işin yapılıp yapılmadığı önemlidir. Bu durum da çalışanlara sıkı disiplinle iş yaptırmak yerine tüm calışanlara sorumluluklar verilerek sürece dahil olmaları sağlanmış ve iç denetçilere olan güven artmıştır. İç denetim hem klasik yönetim anlayışı için hem de TKY anlayışı için oldukça önemli ve disiplin gerektiren bir kavramdır. İç denetim, işletme içi ve işletme dışı çıkar gruplarına hizmet verilmesi, süreçlerin düzenlenmesi, gerekli analizlerin yapılması, değerlendirilmesi ve iyileştirilmesi fonksiyonları ile TKY'ye destek veren ve TKY'yi geliştiren bir unsur olarak görülmektedir. Şekil 4'de İç denetim ve TKY arasındaki 
karşllıklı etkileşim ve birlikte ilerleyen bir döngü içerisinde birbirlerini nasıl etkiledikleri görülmektedir (Özçelik, 2008, s.105).

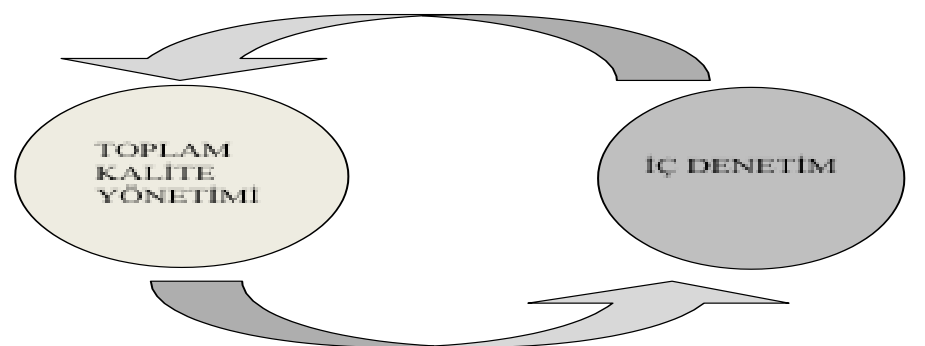

Şekil 4. İç Denetim ve Toplam Kalite Yönetimi Arasındaki Etkileşim

İç denetim, işletmelerdeki kalite ile ilgili yapılan faaliyetlerin etkin ve verimli olarak gerçekleşmesini ayrıca TKY amaçlarından biri olan kalite maliyetlerinin azaltılmasını sağlayan bir yönetim unsurudur. TKY'nin yönetim araçlarından olan kalite kontrol ve iç denetim birbirinden ayrı kavramlardır. Kalite kontrol, kalitenin belirlenen standartlara uygun olup olmaması ile ilgilenirken iç denetim, işletmedeki tüm faaliyetlerin değerlendirilmesi olarak görülmektedir.

Geçmişten günümüze kadar ki işletme yönetim tarzlarındaki değişikliklerden sonra ortaya çıkan TKY anlayışı denetim kavramına yeni bir bakış açısı sağlamıştır. Denetimler ise karmaşık ve dinamik bir yapıda oldukları için sürekli yenilenerek TKY uygulamasında etkinlik ve verimliliğin artmasına olumlu katkı sağlamıştır.

Şekil 5'te İç Denetim sisteminin TKY sistemine etkisi görülmektedir. İç Denetim sistemi, Finansal Denetim, Faaliyet Denetimi, Uygunluk Denetimi ve Bilgi Sitemleri Denetiminden oluşmaktadır. İç denetim ile uygulanan Faaliyet ve Uygunluk Denetimleri TKY sistemini etkilemektedir. Bu durumda kalite maliyetlerinin denetimi sağlanarak maliyetleri en aza indirgenmesi amaçlamaktadır (Özçelik, 2008, s.108). 


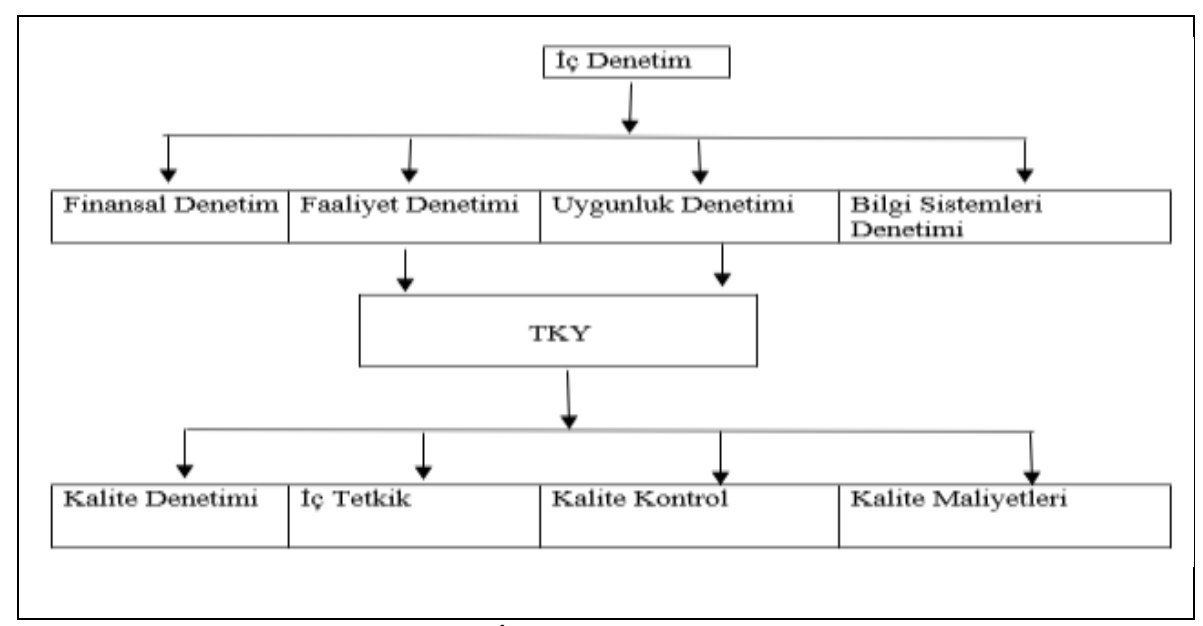

Şekil 5. İç Denetimin TKY'ne Etkisi

TKY'nin bileşenlerinden olan kalite güvence sistemi, ürün tasarım aşamasından, dağıtım aşamasına ve sonrasına kadar, ürün kalitesinin belirlenmesi ve güvence altına alınmasıdır. Kalite güvence sistemi TKY'nin başlangıç noktası olarak kabul edilmektedir. İşletmeler öncelikle müşterilerine ve ortaklarına kalite güvence hizmeti sunarak güven oluşturmalıdır. TKY'nin asıl amacı hata oluşmadan önce önlemlerin alınmasını sağlamaktır. Bu durum sadece kalite kontrol birimi tarafından değil tüm çalışanlar tarafından gerçekleştirilmektedir. İşletmelerde uygulanan iç denetim raporlarının sonuçları, TKY çerçevesinde gerçekleşen faaliyetlerin etkinlik ve verimliliğini tespit etmek ve gerekli önlemlerin alınmasını sağlamak için kullanılmaktadır. İşletmelerde uygulanan iç denetimler işletme üst yönetimi tarafından belirlenen iç denetçiler tarafından yapılmaktadır. İç denetimi gerçekleştiren iç denetçilerin doğru değerlendirme yapabilmesi için TKY kavramının ne olduğunu bilmeleri ve buna uygun değerlendirme yapabilmeleri gerekmektedir. İç denetçilerin doğru yönlendirmesiyle odak noktası müşteri memnuniyeti olan TKY'nin, müşteri memnuniyetinin sağlanması ve müşteri şikayetlerinin azaltılması için belirli aralıklarla kontroller ve denetimler yapması ile güven kazanabilmesi için standartlaşmanın olması gerekmektedir. 
Tablo 1. Kalite Yönetim Sistemi ve İç Kontrolün Karşılaştırılması

\begin{tabular}{|c|c|}
\hline \multicolumn{2}{|c|}{ Kalite Yönetim Sistemi ve İç Kontrolün Karşıllaştırılması } \\
\hline İç Kontrol Sistemi & Kalite Yönetim Sistemi \\
\hline Risk vardır & Risk yoktur. \\
\hline $\begin{array}{l}\text { İ̧̧letmedeki iş süreçlerinin belirlenmiş } \\
\text { olması yeterli olmaktadır. }\end{array}$ & $\begin{array}{l}\text { İşletmelerdeki iş süreçlerinin var olup olmadığını } \\
\text { ve bu süreçlerin kriterlerinin belirlenip } \\
\text { belirlenmediğine bakmaktadır. }\end{array}$ \\
\hline Şekiller oldukça önem arzetmektedir. & Şekiller değil içerik ve etkililik önemlidir. \\
\hline $\begin{array}{l}\text { Yönetim alanlarında risk unsuru } \\
\text { taşıyanların denetim ve iyileştirilmesi } \\
\text { önceliği bulunmaktadır. }\end{array}$ & $\begin{array}{l}\text { Yönetim alanlarında sürekli iyileştirme anlayış1 } \\
\text { söz konusudur. }\end{array}$ \\
\hline $\begin{array}{l}\text { İç kontrol sistemi işletmedeki } \\
\text { faaliyetlerin etkinlik ve yeterliliği gibi } \\
\text { amaçlarına ulaşma konusunda güvence } \\
\text { vermek amaciyla oluşturulmuş, kanun ve } \\
\text { düzenlemelere uygun olan, işletme } \\
\text { yönetim ve iç denetçiler tarafindan } \\
\text { gerçekleştirilen süreçtir. Iç kontrol } \\
\text { sistemi sayesinde işletmenin y1llik } \\
\text { faaliyet raporları ile iç denetim sonucu } \\
\text { oluşturulan raporlar birbirine paralel } \\
\text { olmakla birlikte güvenilirlik dereceleri } \\
\text { yüksektir. }\end{array}$ & $\begin{array}{l}\text { Kalite yönetim sistemi, bir kuruluşu kalite } \\
\text { açısından yönlendiren ve kontrol eden yönetim } \\
\text { sistemidir. KYS işletmenin belirli standartın } \\
\text { üstünde ürettiklerini sertifikasyonlarla belirleyip } \\
\text { güvence altına almaktadır. }\end{array}$ \\
\hline
\end{tabular}

TKY ile İç Kontrol sisteminin birbirlerine benzer noktalarının fazla olmasının yanında farklılıkları da bulunmaktadır. Bu farklılıklar Tablo 1 de belirtilmiştir (https://slideplayer.biz.tr/slide/2883257/ 22.05.2019).

\section{Sonuç}

Teknolojinin hızla ilerlemesi ve küreselleşmenin hızla yayıldığı günümüz dünyasında ekonominin lokomotifi olan işletmelerin, acımasız rekabet ortamında varlıklarını devam ettirebilmeleri, rakiplerine karşın üstünlük sağlayarak pazar paylarını artırabilmeleri açısından Toplam Kalite Yönetimi ve iç denetim oldukça önem arz etmektedir. İşletmelerde kalite kavramı üzerine yoğunlaşan Toplam Kalite Yönetimi, tüm çalışanların katılımı ile gerçekleştirilen ve sınırsız olan müşteri ihtiyaç ve gereksinim- 
lerini karşılarken maliyetleri minimuma indirgeyen bir yönetim felsefesidir. İç denetim ise gerek mali gerekse mali olmayan verilerin alanında uzman kişilerce sistematik bir biçimde değerlendirilmesi anlamına gelmektedir.

Çalışma süresince yapılan literatür taramalarında ülkemizde İç denetim ve TKY etkileşimi ile ilgili yeterli araştırma yapılmadığ görülmüştür. Ülkemizde yakın tarihte bilinmeye başlayan ayrıca tam ve doğru anlaşılmayan iç denetim uygulamalarında TKY faaliyetleri inceleme dışında bırakılmıştır. Çalışma sonucunda TKY ve İç denetim sistemlerinin birbirleri ile olan etkileşimi görülmüştür. TKY ve iç denetim kavramlarının doğru uygulanması sonucunda etkinlik ve verimliliğin arttığı belirlenmiştir. TKY'deki "önce insan" anlayışının olması iç denetçilerin çalışanlara, çalışanların da iç denetçilere olan bakış açısını değiştirmiştir. TKY'yi doğru anlayan iç denetçiler, hata odaklı ve çalışanlara suçlu gözüyle bakmak yerine onlara yol göstererek işletmeye karşı sorumululuklarının farkına varmalarını sağlamaktadır. Bu durum çalışan motivasyonunu artırmaktadır. İşletmede gerçekleştirilen denetimlerin sadece işletme çalışanlarından oluşan iç denetçiler tarafından değil belirli dönemlerde bağımsız denetçiler tarafından denetlenmelerinin de faydası olacağı ve iç denetimlerin TKY uygulamalarından kaynaklanan maliyetleri düşürdüğü ve verimliliği artırdığı tespit edilmiştir. 
EXTENDED ABSTRACT

\title{
Evaluation of Internal Audit from Total Quality Management
}

\author{
* \\ Alirıza A $\breve{g}$ - Elif Çil \\ Bayburt University-Bayburt Provincial Telecom Directorate
}

In this study, the interaction of Total Quality Management and Internal Audit System, which has been interacting with each other throughout history, has been examined. In the results of working; It was found that the Internal Audit System and Total Quality Management System directly or indirectly affect each other and add value as a result of which the Internal Audit function in the enterprises reduces the costs resulting from Total Quality Management applications and increases efficiency.

TQM, which is adopted to provide superiority in today's businesses in a competitive environment, is a management approach that ensures that the needs and requirements of the customers are correctly identified, increased customer satisfaction and reduces costs. In order to determine that businesses use their assets correctly and effectively, it should be evaluated from a free and impartial perspective (Yurdbulan, 1998, p.1). Customer satisfaction is the focal point of TQM and building trust in customers is very important. In order to build this trust, the concept of internal audit has emerged. Inner control; It is defined as an independent, impartial assurance and consultancy system made to improve the activities of an organization and to add value to these activities (Özçelik, 2008, p.1). Internal audits contribute to the effective and efficient realization of quality studies in the enterprises and to reduce the quality costs. In today's world where the concept of quality is important, TQM and Internal Audit, one of the management elements, have influenced each other directly or indirectly throughout history and contributed positively to each other. 


\section{Quality Concept and Total Quality Management}

The concept of quality first BC. In the 18th century Mesopotamia, the oldest and best preserved history of the 282-item Hammurabi laws were found. In the relevant law, If a construction worker builds a house for a man and the house is not strong enough and collapses on the landlord and causes his death, the head of the construction worker is blown off ", the importance given to quality at that time is mentioned. The concept of quality is a constantly evolving and improving concept. After the products were produced after the industrial revolution, inspectors emerged and defective products were prevented from reaching the consumer. This was positive for consumers but costly for manufacturers. After the 1920s, occasional checks were made during the production of the product and compliance with the standards was determined. After World War II, systems have emerged to provide confidence to the customer receiving the product or service. After the 1980s, the concept of Total Quality Management, which spread all over the world, emerged.

With TQM, the companies whose main purpose is to make more profit, make less mistakes by taking the necessary measures before the product is produced and especially the failure costs are reduced. Implementation results of the TQM system applied in enterprises can be summarized as follows (Macdonald, 1999, p.13):

- Very well developed product or service emergence,

- Increased production,

- Effective communication between senior management and employees,

- Satisfied workforce resulting from motivating and rewarding employees,

- Increased market share in the long term,

- Opportunity for profit increase. 


\section{Quality Assurance System}

The quality assurance system is very important for the implementation of Total Quality Management. Quality assurance systems include duties and responsibilities identified within the framework of policies and procedures. The quality handbook, in which all these procedures are collected, constitutes the philosophy of Total Quality Management (Kocabaş, 2013, p.1)

\section{Quality Inspections}

Quality audits; studies and the results of these studies are defined as independent systems that measure the compliance of the specified objectives. Necessary nonconformities are detected by quality audits and necessary measures are taken. Thus, the nonconformities that arise are either reduced or completely eliminated. Quality audits are divided into two. These are Internal Quality Audits and External Quality Audits.

\section{Internal Audit System and Internal Control System}

With the increase in technological developments, it is important to establish an internal control system and to carry out internal audits in order to create trust for customers. Internal audit was first used in non-profit and governmental enterprises.

Internal auditing means an independent assurance and consulting activity to improve and add value to the activities of an organization. In other words; internal audit means the process of systematic evaluation of financial and non-financial activities and controls by internal auditors.

Relationship between Total Quality Management and Internal Audit System

Internal audit is a management element that ensures that the qualityrelated activities in the enterprises are carried out effectively and efficiently, as well as reducing quality costs, which is one of the TQM objectives. Quality control and internal audit, which are the management tools of TQM, are separate concepts. While quality control is concerned with 
whether quality is in compliance with established standards, internal audit is seen as the evaluation of all activities in the enterprise.

The concept of TQM that emerged after the changes in business management styles from past to present has provided a new perspective to the concept of audit. As the audits are complex and dynamic, they have been continuously renewed and contributed positively to increasing efficiency and efficiency in TQM implementation. Internal Audit system consists of Financial Audit, Activity Audit, Compliance Audit and Information Systems Audit. Internal Audit and Activity and Compliance Audits affect TQM system. In this case, it aims to control the quality costs and minimize the costs.

\section{Kaynakça / References}

Akpınar, E. (2006). Kamu yönetiminde denetim olgusu ve Türkiye'de kamu yönetiminin denetlenmesi, Yayınlanmamış Yüksek Lisans Tezi, Süleyman Demirel Üniversitesi SBE, Isparta.

Aktuğoğlu, M. (1986), Denetleme ve revizyon, İzmir: Bilgehan Basımevi.

Aras, A. (2005). Sürdürülebilir süreç yönetimi, İstanbul: Kalder Yayınları, Sistem Matbaacilık.

Atay C. (1999). Devlet yönetimi ve denetimi, 2. Basım, İstanbul: Alfa Aytimur, S. (1999). Denetçinin el kitabı, İstanbul: Kalder Yayınları. Başpınar, A. (2005). Türkiye'de ve dünyada denetim standartlarının oluşumuna genel bir bakış, Maliye Dergisi, 148, 35-62.

Bozkurt, N. (1995). Bağımsız denetimde iç denetim yapısının tanınması ve denetim riskinin değerlendirilmesi, Marmara Üniversitesi, Sosyal Bilimler Enstitüsü Dergisi, Cilt 1, Sayı 2, 29-34.

Dalak, G. (2000). Denetim ve kalite denetimi, Muğla Üniversitesi SBE Dergisi, 1(1), 65-79.

Ertuğrul, İ. (2014). Toplam kalite kontrol, Bursa: Ekin Yayınevi.

Gürbüz H. (1995). Muhasebe denetimi, 4. Basım, İstanbul: Bilim Teknik Yayınevi

http://www.denetimnet.net/UserFiles/Documents/DeloitteMakaleleri/i\%C5\%9FLETMELERDE\%20Ba\%C5\%9Far\%C4\%B1\%20Fakt\%C3\%B6rleri.pdf, 25.05.2019. https://slideplayer.biz.tr/slide/2883257/ , 22.05.2019 
Karcığlu R. ve Yanık R. (2010), uluslararası iç denetim standartları ve Türkiye'nin ilk 500 büyük sanayi kuruluşunda bir uygulama, Atatürk Üniversitesi İktisadi ve İdari Bilimler Dergisi, 24(4), 229-241.

Kaval, H. (2008). Uluslararası finansal raporlama standartları (IFRS/IAS) uygulama örnekleri ile muhasebe denetimi, Ankara: 3. Baskı.

Kocabaş, C. (2013). Kalite güvence sistemi ve standartları, Yayımlanmamış Ders Notları, Karadeniz Teknik Üniversitesi, Trabzon.

Köksal E. (1974). Türkiye'de merkezi hükümetin taşra örgütünü denetimi, Amme İdaresi Dergisi, 7(1), 51-61.

Macdonald, J. (1999). Bir haftada toplam kalite yönetimini anlama. (Emel Köymen çev.), İstanbul: Dünya Yayınları.

Ökten, G. (2004). İç kontrol sistemi yönetimi ve operasyonel risk yönetimi ile entegrasyon, İç Denetim, 3(10), 30-31.

Örnek, A. (1992). Kamu yönetimi, İstanbul: Meram Yayın Dağıtım.

Özçelik, H. (2008). İşletmelerde toplam kalite yönetimi uygulaması ve iç denetim ilişkisi, Yayınlanmamış Yüksek Lisans Tezi, Marmara Üniversitesi İşletme Anabilim Dalı Uluslararası Kalite Yönetimi Bilim Dalı, İstanbul.

Özeren, B. (2000). İç denetim standartları ve mesleğin yeni açılımları, Ankara: Sayıştay Yayınları.

Özevren, M. (1997). Toplam kalite yönetimi:Temel kavramlar ve uygulamalar, İstanbul: Alfa Yayınları 1. Basım.

Öztürk, M. (2003), Fonksiyonları Açısından İşletme ve Yönetimi, İstanbul: Papatya Yayınları.

Pehlivanlı, D. (2010). Modern iç denetim, İstanbul: Beta Basım Yayım Dağıtım.

Sawyer, L. (1988). Sawyer's internal auditing, the practise and modern internal auditing, revised and enlarged, the institute of internal auditors, Florida: Altamonte Springs.

Schiff, J.B. ve May, C.B. (1990). What is internal control? Who owns it, New York: Management Accounting Inc., November .

Sezal, L. (2006). Banka işletmelerinde etkin bir iç denetim ve risk yönetim sisteminde karşılaşılan sorunlar ve çözüm önerileri, Yayınlanmamış Doktora Tezi, Çukurova Üniversitesi, Sosyal Bilimler Enstitüsü, İşletme Anabilim Dalı, Adana.

Şimşek, M. (1998). Kalite yönetimi, İstanbul: Alfa Basım Yayım Dağıtım. 
Tütüncü, Ö. (1998). Konaklama işletmelerinde kalite güvence sistemi içinde kalite maliyetlerinin analizi, Doktora Tezi, Dokuz Eylül Üniversitesi, Sosyal Bilimler Enstitüsü, Turizm İşletmeciliği Anabilim Dalı, İzmir.

Uzay, Ş. (1999). İşletmelerde iç kontrol sistemini incelemenin bağımsız dış denetim karar sürecindeki yeri ve Türkiye'deki denetim firmalarna yönelik bir araştırma. Ankara: Pelin Yayınları.

Yurdbulan, O. (1998). İç denetimin çalışma alanı ve bir uygulama çalışması, Yayınlanmamış Yüksek Lisans Tezi, İstanbul Üniversitesi Sosyal Bilimler Enstitüsü İşletme Fakültesi Muhasebe Anabilim Dalı, İstanbul.

Yükçü, S. (1999). Kalite maliyetlerinin muhasebeleştirilmesi. İzmir: Anadolu Matbaacilik.

\section{Kaynakça Bilgisi / Citation Information}

A $\breve{g}$, A. ve Çil, E. (2019). Toplam kalite yönetimi açısından iç denetimin değerlendirilmesi. OPUS-Uluslararası Toplum Araştırmaları Dergisi, 12(18. UİK Özel Say1s1), 983-1006 DOI: 10.26466/opus.584135 . 